\title{
Improving English Reading Comprehension: The Role of Visual Mind Mappingin SQ4R Strategy
}

\author{
$1^{\text {st }}$ Nurul Lailatul Khusniyah ${ }^{1}, 2^{\text {nd }}$ Yumna Rasyid, Ninuk Lustyantie ${ }^{2}$ \\ \{lailakhusnia5@gmail.com ${ }^{1}$ \} \\ Language Education, Postgraduate of State University, Indonesia ${ }^{12}$
}

\begin{abstract}
The purpose of this research is to increase the English reading comprehension ability through the survey, questions, read, record, recite, review strategy (SQ4R) that is implemented by the role of visual mind mapping. SQ4R is the systematic strategy that can be used varying the media. The method of research is Exploratory Mixed Method. The procedure of research used John Elliot model. The data was collected through observation, interview, daily note, and test. The technique of data analysis is qualitative and quantitative. The research finding shows that visual mind mapping in SQ4R strategy implementation gave the different ways. It has a significant influence on English reading comprehension ability. The average reading comprehension test in the last cycle is 88
\end{abstract}

Keywords: English, Reading Comprehension, SQ4R, Visual Mind Mapping

\section{Introduction}

Reading skills can help students to understand the life. Because through reading activities, everyone can have a lot of knowledge needed in everyday life. Therefore, reading skills are in reading comprehension that has an important role. Reading comprehension is important, not just for understanding text, but for broader learning, success in education, and employment. It is even important for our social lives, because of email, text, and social networking sites. Reading comprehension is a complex task, which requires the orchestration of many different cognitive skills and abilities.[1] Therefore, reading comprehension is related to the learning process and academic achievement. So, it has become a field of educational studies like as in higher education or college program.

One of the English Education Study Programs at State Islamic University Mataram has language learning that focuses on improving language skills such as reading comprehension skills. Reading comprehension subject are given for four semesters and learning outcomes can affect the achievement of learning objectives expected from the vision and mission of the Study Program. Reading comprehension subject is one of the curriculum maps of the English Language Study Program which contribute greatly to the graduates' language skills competencies that will be implemented in the social life of the community. But, the result of learning is not appropriate with the learning goals.

The result of observations and interviews conducted researchers in the English department Islamic University Mataram showed that the students still have difficulty to construct their comprehension in reading learning. It has the impact to their comprehension when they have to 
use the English books. The problem of learning reading comprehension, among others (1) students still have difficulty interpreting the meaning of the text in the reading that is caused by a) identification of the meaning of words and sentences literally or context; b) synthesize words, phrases or sentences into the right meaning as desired by the author's context; c) it is difficult to identify the main idea in the text; d) it is difficult to determine conclusions in the text. (2) Reading sources are less varied; (3) there are still many students who have low grades and do not meet the minimum standard score of graduation of 56-65 (2.00-2.75) to pass a course.

The problem of reading comprehension learning is also caused by the application of learning strategies that have not been maximized. Lecturers have used task-based learning models for students at the beginning of semester 1 . This learning model should provide students with flexibility in understanding reading. Task-based language learning offers many advantages because this learning model is based on communication and requires students to transfer knowledge that has been obtained previously in the context of new knowledge. This is very appropriate for learning reading comprehension. However, it is known that the results of the implementation of task-based learning have not been achieved. Students tend to be more silent and less active in class. The exercises given are not completed. In addition, students experience many difficulties in understanding the context of reading content.

Problems arise because the process of reading comprehension is a complex learning process.It requires a linkage between the learning activities, the learner's experience and the learner's prior knowledge to form the meaning of a text. It also requires the formulation of mental images and visual perception of symbols and written words. Zeki[2], Moore and Lo [3], and Lipson and Wixton[4] discussed the visual images which are created inside the brain and pointed out that the brain creates a visual world and the process of seeing and understanding happen at the same time. Thus, the reading comprehension process needs an appropriate strategy to increase students' reading comprehension ability. The solution is changing the task-based learning with SQ4R strategy. To maximize the implementation of the SQ4R strategy, it requires learning media that are able to provide students with visualization of the application of their knowledge.

Visual and verbal instructional techniques can help overcome cognitive capacity limitations by utilizing the subsystems of working memory more efficiently. Thus, reading comprehension is enhanced when visual and verbal information is utilized and linked in the working memory. When children are encouraged to visualize story content and to enter into dialogue with others it elaborates and deepens the quality of their mental representations. It also enables the reader to make connections between verbal and visual content in a much more integrated way. Thus, the quality of a reader's mental model will be enhanced by the quality of the linking of information within working memory.[5] So, the visual mind mapping included in strategy learning implementation, like as Survey, Question, Read, Reflect, Recite, Review (SQ4R) Strategy. SQ4R is a development of SQ3R; this strategy has added one more R to remind students in determining or making notes. In many strategies, a one-step abandon weakens the system.[6]Because SQ4R requires the network of connected and related concept.

The visual mind mapping is a type of graphic organizer. It is a visible drawing to what happens in the process of storing information in the brain. [7] It is an important and a useful learning strategy as it helps learners to learn, write down their notes, and organize these notes effectively and easily retrieved.[8] The mind maping is also an effective tool in helping low learners to improve their level of achievement. [9] It also improves cognitive processes and long-term memory of facts. Besides, it encourages using deeper levels of factual processes and better reorganizing the memory.[10] These opinions have been appropriate with the SQ4R application in enhancing English reading comprehension. In Başar and Gürbüz research, a 
significant difference was found in the reading comprehension skills in favour of the students who studied reading comprehension with the SQ4R technique.[11] Al-Ghazo has studied the effect of SQ3R and semantic mapping strategies on reading comprehension learning.[12]

There are many studies were conducted to investigate the mind map on reading comprehension. Talal Mohaidat showed that the effect of applying the electronic mind maps in teaching reading texts was medium.[13]E-mapping is a potentially powerful active learning tool which goes beyond developing strong reading skills and enhancing class participation. [14]The same studied by Phantharakpong and Pothitha about the development of English reading comprehension by using concept maps.[15]Therefore, the aims of the study are to find the effect of visual mind mapping in SQ4R strategy implementation on English reading comprehension ability for the students in the second semester at English Department at State Islamic University Mataram.

\subsection{Statement of Problem}

Based on the problem above, the formulation of the problem in this research as follows;

How is the process of visual mind mapping in SQ4R strategy implementation on English reading comprehension learning?

How is the effectiveness of visual mind mapping in SQ4R strategy implementation on English reading comprehension learning?

\section{Literture Review}

\subsection{Reading Comprehension}

Reading and literary scholars have created their own definitions of reading comprehension that contain a bit more precision. According to Harris and Hodges, reading comprehension is the construction of the meaning of a written communication through a reciprocal, holistic interchange of ideas between the interpreter and the message. Thomas Barrett has suggested the following three types of action with his three-level taxonomy of reading comprehension; 1) literal comprehension; 2) inferential comprehension; and 3) critical comprehension.[16] Reading may be considered the process of recognition and perception of the written or printed material. On the other hand, comprehension is the understanding of the meaning of the written material and covers the conscious strategies that lead to understanding. [17] So, it is concluded that the assumption of meaning in reading comprehension is a way of solving problems and the process of thinking interpreters. Reading comprehension causes action from the reader. This action involves the use of knowledge where the reader has a text topic such as the text itself. The problem that arises in reading comprehension is to make meaning from the text.

Reading comprehension as the process of simultaneously extracting and constructing meaning through interaction and involvement with written language. We use the words extracting and constructing to emphasize both the importance and the insufficiency of the text as a determinant of reading comprehension. Comprehension entails three elements;[18]

The reader who is doing the comprehending

The text that is to be comprehended

The activity in which comprehension is a part 
These three dimensions define a phenomenon that occurs within a larger sociocultural context that shapes and is shaped by the reader and that interacts with each of the three elements. The identities and capacities ofreaders, the texts that are available and valued, and the activities in which readers are engaged with those texts are all influenced by, and in some cases determined by, the sociocultural context. The sociocultural context mediates students' experiences, just as students' experiences influence the context. We elaborate on each element in subsequent sections. Reader, text, and activity are also interrelated in dynamic ways that vary across prereading, reading, and post-reading.

The learning process of reading comprehension in this research consists of three elements. The first element is a text consisting of various types of reading with the construction of the message to be conveyed. Second, is the reader who is influenced by factors that come from the student. These factors influence the mindset of students in constructing meaning. Third, is an activity that can be done individually or in groups. Reading comprehension activities can be done at school, home or workplace. These three elements are also influenced by socio-cultural conditions and context.

\subsection{Survey, Questions, Read, Record, Recite, Review (SQ4R) Strategy}

One of the first textbook reading systems, SQ3R, was developed by Francis P. Robinson in 1941. The letters in the name of this system represent the five steps: survey, question, read, recite, and review. You may encounter other reading systems in your various textbooks, but when you analyze the steps in those systems, you will notice that many involve different labels for essentially the same steps because these steps are powerful processes that are proven to increase comprehension and enhance learning. SQ4R is a six-step system for reading and comprehending textbook chapters: survey, question, read, record, recite, and review. SQ4R is based on SQ3R; a fourth "R" has been added to the system to remind students to take notes. As with any approach, skipping anyone step weakens the system. Here are the steps of SQ4R;[19] Step One: Survey the Chapter Surveying a chapter requires less than twenty minutes of your time. Surveying provides you with a preview of the chapter's contents, familiarizes you with the chapter features, and begins the process of activating or creating schemas upon which you can attach details.

Step Two: Write Questions During the question step, turn the chapter title and each heading and subheading into a question. The ten or twenty minutes it takes to write questions is time well spent. You get one additional overview of the chapter, and you create a purpose for reading, focus your attention on upcoming information, and activate working memory.

Step Three: Read Carefully Some students feel that they should be able to "read fast" to get through chapters. Others read chapters - only to find at the end of the chapters that they do not remember much of what they had just read; consequently, they must reread at least one more time. The read step of SQ4R encourages you to read carefully and thoroughly.

Step Four: Record Information After you read a paragraph or a section of information carefully, begin the recording step by taking notes of the important information you will need to study, memorize. Taking time to record information (take notes) benefits you in many ways. First, your notes become a reduced or a condensed form of the information you need to study and learn. Second, taking notes keeps you actively involved in the learning process and reduces the tendency for you to shift into automatic pilot, a state of mind where you mechanically read without processing information clearly. Third, taking notes holds information in working memory and provides more time for you to encode it for your long-term memory.

Step Five: Recite Before you move on to the next paragraph, stop and use the recite step. Without looking at your notes or the textbook, recite the important points you read in the 
paragraph and recorded in your notes. Look back at the textbook or your notes to check your accuracy. Continue to move through the chapter by using the Read-Record-Recite Cycle. The Read-Record-Recite Cycle is a thorough reading strategy that involves reading a section of information, taking notes, and explaining theinformation out loud before moving to new information. When you have completed this cycle for the entire chapter, move on to the final step of SQ4R.

Step Six: Review The review step, which includes both immediate and ongoing review.

\subsection{Visual Mind Mapping}

The ultimate organizational thinking tool, the easiest way to put information into our brain and to take information out of our brain. It is a creative and effective means of note taking that literally "Maps out" your thought." The human brain consists of 2 halves which are responsible for different purposes. The left side is in charge of logic, words, arithmetic, linearity, sequences, analysis and lists. The other side of the brain is in charge of multidimensionality, geometry and synthesis. Studies show that humans can respond very well to words, images, colour and direct association. Buzan defined these features of the human brain to develop a set of rules which is simple to follow in order to create a maze of information called the mind map (Buzan). The concept of mind mapping has existed for many decades but it was only made popular by Tony Buzan in the 1960s. His initial intention is to allow the user to organize and recall conceptual information in a more effective way. [20]Budd, "a mind map is an outline in which the major categories radiate from a central image and lesser categories are portrayed as branches of larger branches".[21] According to Kotcherlakota, Zimmerman, \& Berger, "mind maps help students clarify their thinking and lay the foundation for in-depth expertise related to their research focus, review of the literature, and conceptual framework."[22]Thus, the visual mind mapping in this study refers to the process used students' brain to describe the story or text.

\section{Methode}

\subsection{Methods and Procedure}

The research is action research that used the exploratory mixed method. The procedure of research used Elliot model that has 3 stages. The first stage consists of identifying key ideas, gathering facts, inventions and analyzes. The second stage contains the actions that are followed by the evaluation step and its influence which then in the stage of improvement for the third stage. The third stage is also the same as the second stage to find good results and success. Measures of action success are seen both from the learning process and learning the result. Action will be declared successful if the student activity in the learning process is to achieve good category marked at least reaches an average score of 75. The process of learning did for 4 weeks. In this action, pre-test and post-test results are too used in order to decide on the effectiveness of the independent variable.

\subsection{Participant of Research}

The participant of research consists of a total 34 students from the English Department at State Islamic University Mataram in 2016-2017 academic years. 


\subsection{The process of Collecting Data}

The process of collecting data for this action research consists of several types;

Observation. It is as documentation and reflection learning process using visual mind mapping in SQ4R strategy application.

The test has three types of component are literal comprehension, inferential comprehension, inferential comprehension and critical comprehension.

Daily note

Interview

\subsection{The technique of Data Analysis}

To determine the reliability of data, the researchers used Lincoln and Guba terms such as credibility, transferability, dependability, and conformability. The descriptive analysis technique was implemented in order to determine the students' activity learning progress for the first problem. The independent t-test technique was implemented to know the result of students' reading comprehension ability before and after application of the visual mind concept of SQ4R strategy.

\section{Finding}

\subsection{The Process of Visual Mind Mapping in SQ4R Strategy Implementation on English Reading Comprehension Learning}

The steps of SQ4R strategy implementation in English reading comprehension learning is completed by visual mind mapping media, as follow;

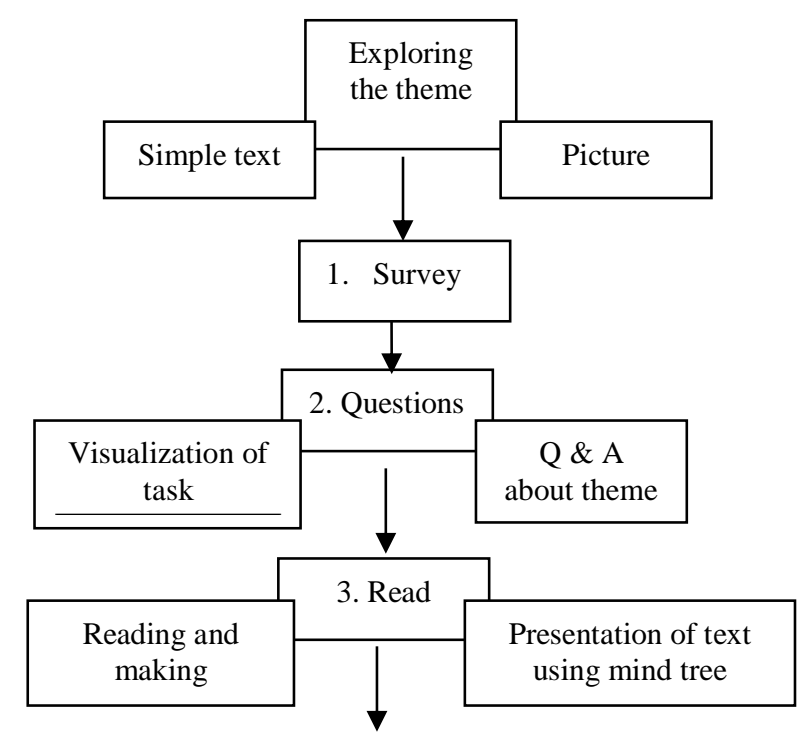




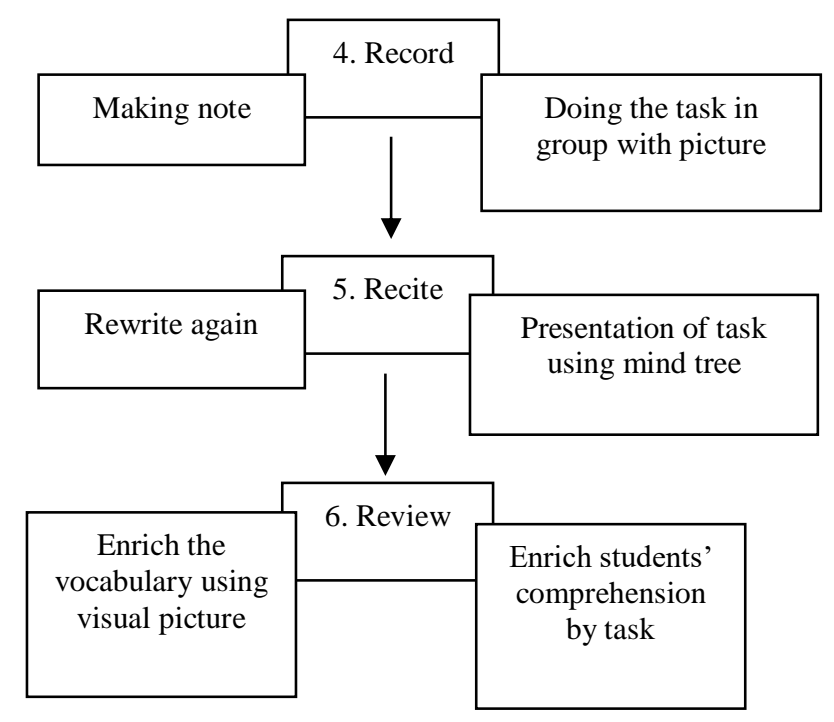

Figure 1. The steps of SQ4R Strategy Implementation by

Visual Mind Mapping in English Reading Comprehension

The process of improving English reading comprehension using the SQ4R strategy completed with visual mind mapping was carried out for 3 cycles. Each cycle consists of 4 meetings for learning the main material and 1 meeting for the final test. So, learning activities to discuss teaching material were conducted in 12 meetings. During the implementation of the action, many researchers found changes in reading comprehension ability. Although the process of increasing capacity from the first cycle to the second cycle has not shown significant progress. But the results of the second cycle to the third cycle showed significant changes.

4.2 The Effectiveness of Visual Mind Mapping in SQ4R Strategy Implementation on English Reading Comprehension Learning 


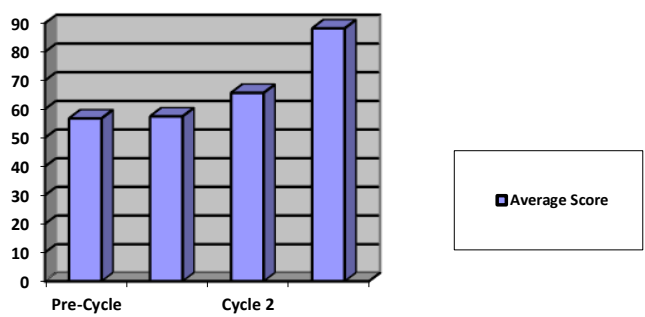

Graph.1. Comparison of Average Score English Reading Comprehension Tests from Pre-cycle to the Third Cycle

In the above graph can be seen that there is improving the average score from pre-cycle until the third cycle. The pre-cycle has the average score of 56.8 that increased in the second cycle is 57.5. In the second cycle has the average score of 65.7 that increased in the third cycle is 88.2. This change can also be seen from the increasing percentage graph, as follows;

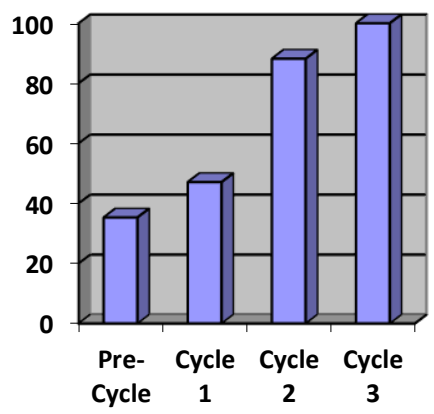

口Percentage

Graph.2 Comparison of Percentage English Reading Comprehension Tests from Pre-cycle to the Third Cycle

The graph above shows the percentage of students who passed the English reading comprehension test or the number of students who had increased English reading comprehension. Students who have an English reading comprehension are based on $100 \%$ standard score. It means that the determination of passed standards that follow the study program rules has been successfully carried out because $100 \%$ of students graduate. Likewise, the rate that has been determined in accordance with the standard of this study is 80 . While the research criteria have reached the percentage level that is good enough to meet the needs of standard 80 score, the action research is stopped. The smallest student scores are in grades $>80$. The number of students who graduate reaches $100 \%$ with a range of score that varies. So it was concluded that from the first cycle to the first cycle and from the first cycle to the second cycle and from the second cycle to the third cycle, there was an increase so large for the average score or percentage level. However, from the second cycle to the third cycle, there was a big change. 
This can also be seen from changes in reading comprehension test scores per level of comprehension, as follows:
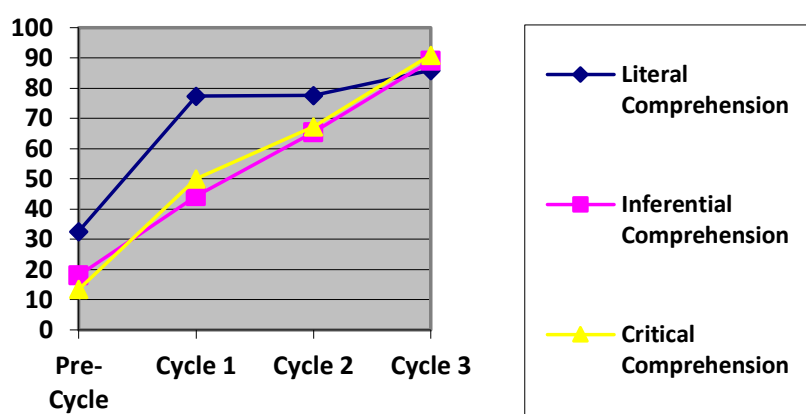

Graph. 3 Comparison of Average Score English Reading Comprehension Tests Per Level of Comprehension from Pre-cycle to the Third Cycle

The graph above concludes that the critical level of comprehension that leads to evaluate ability has the highest average value compared to other levels of understanding. The second position for the average value of English reading comprehension is inferential understanding followed by the third position is literal understanding.

\section{Discussion}

The difference in learning activities in reading comprehension in each cycle is explained below.

In the first cycle, researchers applied the SQ4R strategy according to the strategy procedure. Learning activities are carried out according to the stages of SQ4R and the time division that has been designed according to the planning of learning. However, in the fifth step, adding the activity of rewriting important things that have not been understood. However, the results of this activity have not shown success in accordance with the objectives. Students tend to just complete the exercise without noting the difficulties faced and vocabulary that is not understood. After the learning process is completed, the researcher conducts reflection activities on the implementation of actions that aim to find out the results of the improvement of students' reading comprehension ability, so that the researcher can determine whether the action activities arecontinued in the second cycle. The results of the first cycle, the ability of students at the level of literal has shown success in accordance with the standards set through the indicator of determining the minimum average score of 80 . While at the level of inferential and critical has not shown a maximum level. This is evidenced by the fact that most of the final test scores of students are still low. Therefore, action research is continued by making a second cycle plan.

The results of the first cycle of reflection concluded that the application of SQ4R must be more varied. Learning activities in the first cycle lack the use of learning media such as visual mind mapping, pictures, videos and online sites related to reading learning. So, the action activities in the second cycle maximize the use of learning media and add simple reading texts 
and exercises from online websites, and still emphasize the activities of rewriting vocabulary or sentences that are not understood by visual mind mapping. It aims to enable students to improve critical thinking patterns so that the process of analyzing reading texts becomes easier. The results of the second cycle of action indicate that there is an increase in literal and inferential levels of reading comprehension. So, students have been able to utilize knowledge about the world and their lives in understanding the reading context. However, students still have difficulty responding to the results of their friend's understanding that has been presented. However, the final test results on critical understanding have not shown in accordance with the standard of success of the actions that have been determined. Thus, the researchers made a replanning for the third cycle.

From the results of the analysis of the finding data in the second cycle, it was concluded that the implementation of the third cycle had been carried out to encourage students to use prior knowledge and be able to respond to the presentation of their friends. The learning time is also maximized to discuss the results of the work (training) of students together. In the second cycle, students have been able to rewrite vocabulary and sentences that are difficult to understand, but it is difficult to respond to the results of the presentation of the exercises that their friends have done. Therefore, the third cycle of action research has also focused on rewriting activities, but writing back information about the things students have presented. This activity was carried out in the fifth step, namely, recite. This was done by researchers to encourage students' critical level that was still low in the first and second cycles. The findings obtained indicate that there is a change in the level of student reading comprehension that is getting faster both starting from the level of literal, inferential and critical comprehension.

Based on the explanation, it was concluded that reading, listening and writing activities can improve English reading comprehension. What has been read and heard must be written by students to help to understand. After several times this activity was carried out, students began to get used to the activity. Just as the success of Khaki's research has found that the right strategy for improving reading comprehension is to summarize and make questions. [23] This has been precisely applied in learning English reading comprehension using the SQ4R strategy that completed visual mind mapping.

The use of SQ4R strategy in reading 2 subject learning at UIN Mataram has succeeded in improving the ability of reading comprehension which has experienced difficulties. Because this strategy can be done individually or in groups easily. The SQ4R strategy provides a complete understanding of information by determining the required reading, repeating learning repeatedly, and storing the information obtained for use at the next learning meeting. In addition, this strategy also increases the activeness of students' critical thinking patterns because it forces students to associate what knowledge or information they have had with reading and developing it. It has also been widely proven from the results of studies examining reading comprehension with reading strategies such as Phantharakpong and Pothitha[24]about reading comprehension in English using the concept of visual mind mapping; Sinambela, et.al[25] about increasing reading comprehension through the KWL strategy; Susanti and Agusni [26] about teaching descriptive reading comprehension through a combination of strategies; Al-Ghazo[27] who tested the SQ3R strategy and the semantic mapping strategy for learning reading comprehension. But in this action research, reading comprehension is intended also to improve understanding of reading texts that refer to 3 levels of comprehension at once through the SQ4R strategy. So that this action research has a different value than the research that is done a lot.

The addition of rewrite activities in the fifth step that is applied to the implementation of the actions of each cycle is the result of the novelty of the action research. This is because the implementation of these activities provides a significant level of success in the ability of 
students' English reading comprehension. Therefore, the results of this study have a major impact on the re-mapping of learning reading courses.

The results of this study recommend to the consortium to maximize the achievement of learning objectives reading comprehension to a critical level in semester 2. Although this study was conducted in semester 2 aimed at achieving the ability to understand reading texts at inferential levels in accordance with the provisions of learning objectives in the study program. But in this case, the researcher still uses 3 levels of reading comprehension. Because researchers believe that students must be given stimulation to reach the highest level. The results of the study showed that the literal level was indeed controlled by students. This is evident from the results of the assessment data from the first cycle. So, it is clear that learning reading 1 subject did not find problems as in reading 2 subjects.

Broadly, the results of this study can be used by the general public. This is because the learning problems of reading comprehension have similar lines every time using learning strategies. The difference in the application of learning strategies lies in classroom settings that are adapted to the background of students. This means that instructors at other universities can use the SQ4R strategy that has been successfully used in learning English reading comprehension. However, they must adjust their implementation in the class according to the characteristics of students and the academic atmosphere or learning process in the classroom. Because each college has a different academic atmosphere and diverse background of student input. This can be understood from the input standards set by the university. The results of this study are also difficult to apply in other universities when problems encountered in learning English reading comprehension have different problems.

Based on the results of data analysis and discussion that has been carried out, this research has implications as follow;

Theoretical implications related to SQ4R strategy. The implementation of this strategy provides a better influence on student learning progress because the SQ4R strategy stage is more flexible and easily understood by students. So, the lecturer does not take long to use this strategy in classroom learning. This strategy can be used in advanced reading courses or other subjects. This is because the basic theory of this strategy is easy and can be adapted to learning needs. Thus, this strategy can be one of the recommended learning strategies especially for the teaching and learning process of reading.

Practical implications, the SQ4R strategy can be applied to large classes with a number of more than 30 students. However, the teachers need harder and optimal effort to design learning classes. As in learning English reading comprehension in reading 2 subjects at UIN Mataram for 34 students who have experienced a lot of difficulties, especially in English reading comprehension, have increased at three levels of comprehension, namely literal, inferential and critical.

For English lecturers, the successful implementation of the SQ4R strategy is one of the choices for the teaching and learning process that can be used in the learning of other courses. So that the results of this study can be used as a guide for designing a syllabus or learning plan for reading the subject. In addition, the results of this study can also be used as a guide for preparing teaching materials that are tailored to the needs and stages in the SQ4R strategy.

For students, learning with the SQ4R strategy can feel more fun. From the results of the research shows that this strategy can build students' thinking patterns more critically and creatively. They have a positive attitude in building peer cooperation or learning environment. In addition, they become more independent in learning.

Managerial implications are aimed at stakeholders, namely policy makers in the English Education Department at UIN Mataram. The English education consortium can utilize the 
results of this study to develop teaching and learning in the varioussubject. The results of the study revealed that the percentage of critical level of comprehension experienced a fairly good increase so that it could be used as a reference to change the achievement of the goal of reading 3 learning that is the critical level entered in reading 2 subjects.

\section{Conclution}

The implementation of SQ4R that completed visual mind mapping is designed through the dominance of the role of students and the use of various learning media to complement the learning process, so that it is more maximal. Learning activities are also carried out with a variety of individual assignments, discussions, peer assessments and presentations.The learning activities of the first cycle in reading comprehension focus on the implementation of SQ4R according to the procedures described by Wong. The learning process of the first cycle shows the ability of inferential and critical understanding levels is still low. The second cycle, learning process focuses on the application of learning media and the context of teaching materials. In second cycle, the mindset of students becomes more critical. In addition, the ability of literal and inferential level of understanding is better. Whereas the third cycle, learning process has emphasized again the rewrite activity in the fifth step. In the fifth step involves the process of reading-note-saving-reading. This activity has made the learning process in class more enjoyable. The ability of students' reading comprehension in level of literal, inferential and critical comprehension becomes better. Rewrite activity is the novelty value of this research.

Each cycle has a variety of interesting learning activities. The steps adopted from the SQ4R strategy include; (1) the first stage is that the survey involves the process of understanding the theme or topic of learning, (2) the second stage is answering the main questions related to the topic, (3) the third stage is reading through detailed and repetitive reading of the text, (4) the fourth stage is recording information that has been obtained in the previous stage and applying it through the activity of working on exercise questions, (5) the fifth step is to repeat the results of reading comprehension, and (6) the sixth step is to review it by giving the results of the analysis. To implement the SQ4R strategy step in learning reading comprehension, teaching materials are designed separately according to the learning sequence in the SQ4R strategy and the needs of the reading 2 subject.

\section{References}

[1] Oakhill, Jane, Elbro, K. Cain, and Carsten, and Teaching Reading Comprehension A Handbook. London \& New York: Routledge, 2015.

[2] A. Zeki, S, Vision of the brain. Oxford Blackwell Scientific Publication, 1993.

[3] C. Moore and L. Lo, "Reading comprehension strategy," J. Int. Assoc. Spec. Educ., vol. 09, pp. 124-127, 2008.

[4] M. Lipson and K. Wixson, Assessment and instruction of reading and writing difficulties, an interactive approach. Pearson Boston, 2009.

[5] Woolley and Gary, "Developing reading comprehension: combining visual and verbal cognitive processes," Aust. J. Lang. Lit., vol. 33, pp. 119-120, 2010.

[6] Wong and Linda, Essential Study Skills Sixth Edition. Houghton Mifflin Company, 2009. 
[7] T. Buzan and B. Buzan, The mind mapping book: How to Use Radiant Thinking to maximize your brain's untapped potentia. London: BBC, 1996.

[8] J. M. Tucker, G. R. Armstrong, and V. J. Massad, "Profiling the mind map user: A descriptive appraisal,” J. Instr. Pedagog., vol. 02, pp. 1-13, 2010.

[9] S. Holzman, Strategy-based learning for English language learner. 2004.

[10] S. Farrand, F. Hussain, and E. Hennessy, "The efficacy of the mind map study technique. Journal of Medical Educational,” vol. 36, pp. 426-431, 2002.

[11] Başar, Murat, and M. Gürbüz, "Effect of the SQ4R Technique on the Reading Comprehension of Elementary School 4th Grade Elementary School Students.International Journal of Instruction," vol. 10, 2017.

[12] Al-Ghazo and Abeer., "The Effect of SQ3R and Semantic Mapping Strategies on Reading Comprehension Learning among Jordanian University Students,” Int. J. English Educ., vol. 04, 2015.

[13] T. Mohaidat and M. Mahmoud, "The Impact of Electronic Mind Maps on Students' Reading Comprehension,” English Lang. Teach., vol. 11, pp. 32-42, 2018.

[14] A. R. Ellozy and H. M. H. Mostafa, "Making Learning Visible: Using E-maps to Enhance Critical Reading Skills,” J. Online Learn. Teach., vol. 6, no. 3, p. 634, 2010.

[15] Phantharakphong, Phatchara, Pothitha, and Suteera, "velopment of English Reading Comprehension by Using Concept Maps, Procedia Social and Behavioral Sciences, Procedia - Social and Behavioral Sciences," vol. 116, pp. 497-501, 2014.

[16] Brassell, Danny, Rasinski, and Timothy, Comprehension That Works Taking Students Beyond Ordinary Understanding to Deep Comprehension. CA: Shell Education, 2008.

[17] M. Khabiri and M. Pakzad, "The Effect of Teaching Critical Reading Strategies on EFL Learners' Vocabulary Retention,Journal Teaching Language Skills,” vol. 04, p. 77, 2012.

[18] Chair, Snow, and Catherine, Reading for Understanding Toward an R\&D Program in Reading Comprehension. Rand, 2002.

[19] Wong and Linda, Essential Study Skills Sixth Edition,. New York: Houghton Mifflin Company, 2009.

[20] Funa, S. Chin, and N. Maskata, "Teacher-Centered Mind Mapping vs StudentCentered Mind Mapping in the Teaching of Accounting at Pre-U Level - An Action Research. International Conference on Learner Diversity," Procedia Soc. Behav. Sci., vol. 07, pp. 240-246, 2010.

[21] J. W. Budd and Mind, "maps as classroom exercises,” J. Econ. Educ., vol. 35, pp. 3536, 2004.

[22] et al Kotcherlakota, S., "Developing scholarly thinking using mind maps in graduate nursing education. Nurse Educator," vol. 38, pp. 252-255, 2013.

[23] Khaki and Nasrin, "Nasrin, Improving Reading Comprehension in a Foreign Language: Strategic Reader. The Reading Matrix,” vol. 14, 2014.

[24] Phantharakphong, Phatchara, and S. Pothitha, "Development of English Reading Comprehension by Using Concept Maps, Procedia Social and Behavioral Sciences, Procedia - Social and Behavioral Sciences," vol. 116, pp. 497-501, 2014.

[25] Sinambela and Erika, "Improving Students' Reading Comprehension Achievement by Using K-W-L Strategy, English Linguistics Research,” vol. 4, 2015.

[26] Susanti, Rika, and Agusni, "Teaching Reading Comprehension Descriptive Text by Combining Polar Opposite Strategy and SQ4R (Survey, Question, Read, Record, Recite and Review) Strategy at Junior High),” Mhs. Bhs. Ingg., vol. 02, 2013. 
[27] Al-Ghazo and Abeer, "The Effect of SQ3R and Semantic Mapping Strategies on Reading Comprehension Learning among Jordanian University Students," Int. J. English Educ., vol. 04, 2015. 
